\title{
BLACK SWANS AND RISK - ASSESSING CONSEQUENCES OF EXTREME EVENTS FOR THE GERMAN BIGHT
}

\author{
Marius UIm, University of Siegen, marius.ulm@uni-siegen.de \\ Arne Arns, University of Siegen, arne.arns@uni-siegen.de \\ Jürgen Jensen, University of Siegen, juergen.jensen@uni-siegen.de
}

\section{BACKGROUND AND INTRODUCTION}

Westerly and north-westerly storms regularly hit the German North Sea coast causing surges of several meters at the dikes. But extreme events like cyclone Xaver in 2013 are not the largest physically possible events on record. Dangendorf et al. (2016) show that the individual components of the total water level (i.e. mean sea level, surge, and tide) were not at their observed maximum during Xaver. The research project "EXTREMENESS" was initiated to examine the meteorological potential of storms in the German Bight and to assess the consequences of extremely large and rare but physically possible storm surge events, so called "black swans".

Our project partners, the German Meteorological Office, the German Federal Waterways Engineering and Research Institute, and Helmholtz-Zentrum Geesthacht, evaluate possible meteorological and resulting hydraulic boundary conditions including regionally projected sea level rise scenarios which we use to simulate inundations in the study area around Emden (Lower Saxony, Germany) (see Figure 1) using a two-dimensional hydrodynamic numerical (2D-HN) model. Large parts of the region are situated below mean sea level and drained using tide gates and pumping stations. Therefore the area is highly vulnerable to dike failures and loads exceeding the design levels of defense structures.

Combining inundation scenarios with exceeding probabilities and dike failure probabilities will yield risk maps, showing the most vulnerable dike sections and pointing out areas that need particular attention in maintenance.

\section{METHODOLOGY}

To simulate the inundations in consequence of a potential dike failure during a black swan event a 2D-HN model of the hinterland around Emden is set up using DHI MIKE 21. In a first step, modeling terrain including dikes, drainage ditches, buildings, and infrastructure allows mapping of affected areas for several dike failure scenarios. The scenarios are based on different failure modes which are described with a particular probability, following the approach of Kortenhaus et al. (2003). As a second step, return periods are assigned to the scenario's boundary conditions using extreme value statistics. The storm surge's probability of occurrence is therefore combined with the individual dike failure probability of each scenario to give a joint occurrence probability. In a third step, combining inundation areas with land use data yields potential tangible damages for each scenario. The study area is characterized by a mixed land use with spacious agricultural land but also residential areas (dense population of approx. 50,000 inhabitants in Emden) as well as industrial areas (e.g. large factories, gas plants). Therefore scenarios with different flood paths may yield significantly different damage estimations. A risk assessment is finally used for comparison. Thereby, the risk is defined as the product of potential damage and the event's previously estimated occurrence probability.

\section{APPLICATION}

The results of the risk assessment will be discussed with local administrations, authorities, and civil protection services as well as with the general public and other stakeholders. The gained knowledge should improve disaster preparedness by revealing the most critical parts of coastal protection in the study area.

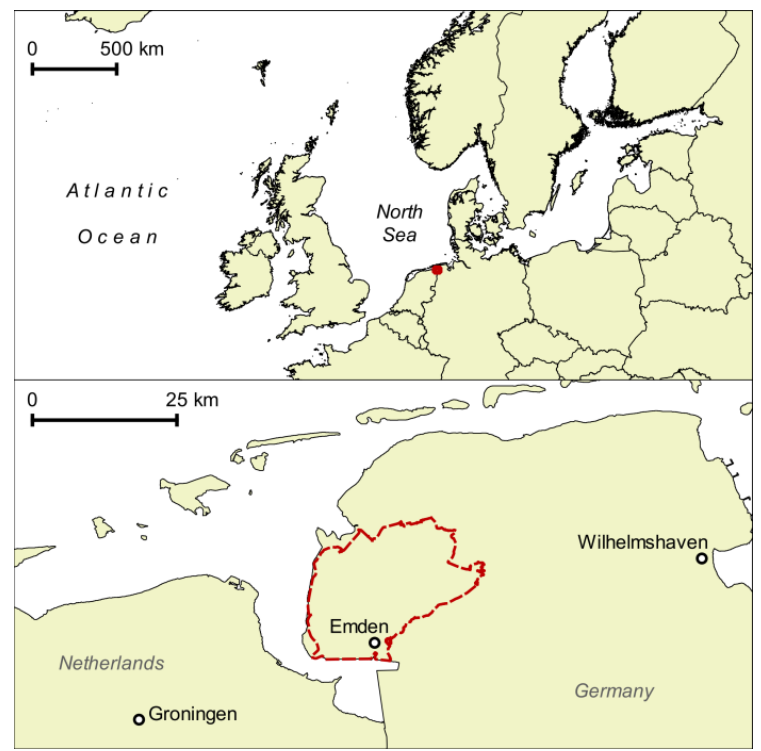

Figure 1 - Study area: overview (top) and detailed map section (bottom) with drainage area (dashed red).

\section{REFERENCES}

Dangendorf, Arns, Pinto, Ludwig, Jensen (2016): The exceptional influence of storm 'Xaver' on design water levels in the German Bight, Environ. Res. Lett., IOP Publ., vol. 11, no. 5, DOI: 10.1088/1748-9326/11/5/054001.

Kortenhaus, Oumeraci, Weissmann, Richwien (2003): Failure mode and fault tree analysis for sea and estuary dikes, Coastal Engineering 2002, Proc. 28th Int. Conf. Coastal Engineering (ICCE), World Scientific, pp. 23862398 DOI: 10.1142/9789812791306_0200.

\section{ACKNOWLEDGEMENTS}

The presented research is part of the project "EXTREMENESS" within the KüNO program, funded by the German Federal Ministry of Education and Research. Project funding number: 03F0758B. 